NASA Contractor Report 198470

\title{
Laser-Induced Incandescence: Detection Issues
}

Randall L. Vander Wal

NYMA, Inc.

Brook Park, Ohio

May 1996

Prepared for

Lewis Research Center

Under Contract NAS3-27186

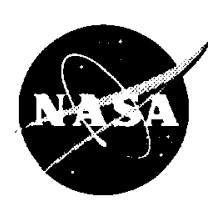

National Aeronautics and

Space Administration 
, 


\title{
Laser-induced Incandescence: Detection Issues
}

\author{
Randall L. Vander Wal* \\ NYMA@ NASA-Lewis \\ M. S. 110-3 \\ 21000 Brookpark Rd. \\ Cleveland, $\mathrm{OH} 44135$
}

\begin{abstract}
Experimental LII measurements were performed in a laminar gas-jet flame to test the sensitivity of different LII signal collection strategies to particle size. To prevent introducing a particle size dependent bias in the LII signal, signal integration beginning with the excitation laser pulse is necessary. Signal integration times extending to 25 or 100 nsec after the laser pulse do not produce significant differences in radial profiles of the LII signal due to particle size effects with longer signal integration times revealing a decreased sensitivity to smaller primary particles. Long wavelength detection reduces the sensitivity of the LII signal to primary particle size. Excitation of LIl using $1064 \mathrm{~nm}$ light is recommended to avoid creating photochemical interferences thus allowing LII signal collection to occur during the excitation pulse without spectral interferences.
\end{abstract}

\section{Introduction}

Laser-induced incandescence (LII) has recently emerged as a versatile laser-based technique for measuring soot volume fraction in a wide variety of systems. Applications of LII have included diesel engines for both qualitative [1] and quantitative [2] measurements, laminar [3-6] and turbulent gas-jet flames [7], and droplet combustion [8]. Other work has explicity tested the dependence of the signal upon soot volume fraction and found excellent linearity $[3,4]$.

While the experimental conditions and other experimental details have been reported from these applications, limited characterization of the technique has been performed $[4,5,9,10]$. Given the lack of experimental guide-lines, heavy reliance upon theoretical modelling of the LII process is used to guide and/or interpret experimental results. A key issue raised by theoretical models of LII is the effect of particle size upon the LII signal $[11,12$, 13,14l. Theoretical models predict that the spectral and temporal character of the LII signal is dependent upon particle size. Such a dependence could affect the soot volume fraction measured by LII and thus would present a limitation to the technique. Alternatively, the dependence of the LII signal upon particle size could perhaps be used to ascertain the particle size through either the spectral or temporal variation of the LII signal. Such a possibility offers an attractive alternative to traditional scattering/extinction methods. In this paper, experimental results are presented assessing the particle size dependence of the LII signal with a view towards minimizing this effect.

\section{Effect of Particle Size Theoretical Prediction(s)}

Current theoretical models of LII, while differing in the predicted heating and cooling rates of different size soot particles, agree in predicting different final temperatures $[12,14]$. This is physically realizable. Near the vaporization temperature of carbon, roughly $4000 \mathrm{~K}$, surface vaporization of material is predicted to be the dominant energy loss mechanism during the laser heating process. Since the energy addition rate scales volumetrically for particles in the Rayleigh size regime, the ratio of the energy loss rate to energy addition rate will scale as $1 / r$, where $r$ is the particle radius.

Theoretical models of the LII signal also predict a particle size dependent cooling rate [12,14] with large particles cooling more slowly than small particles at a given temperature thus further biasing the LII signal towards larger particles. This is also physically realistic since the cooling processes of vaporization and convection depend not upon the particle volume but rather upon the particle surface area even though the particle volume determines its heat content. Thus the ratio of energy loss rate to stored energy similary scales as $1 / r$.

If smaller particles reach lower final temperatures after the excitation laser pulse, they will contribute fractionally less to the LII signal with decreasing detected wavelength. With longer detection times after the laser pulse, this effect will become more pronounced due to the different cooling rates of different size particles. The magnitude of particle size bias affecting the LII signal through the heating/cooling

\footnotetext{
*Corresponding author

Proceedings of the 1996 Technical Meeting of the Central States Section of the Combustion Institute.
} 
processes and detection wavelength is dependent upon what range of soot particle sizes is relevant to LII. For example, a recent treatment shows temperature variations of $>1000 \mathrm{~K}$ for particle sizes ranging from $10-1000 \mathrm{~nm}$ [14].

\section{Implications for Signal Collection}

Since practical signal collection strategies involve integrating the LII signal both during and for some time after the laser pulse, the details of the heating process are less important than the final particle temperature after the laser pulse affecting both the incandescent spectral distribution and decay rate.

Previous experimental measurements have also shown that morphological changes occur within the primary particles upon laser-heating [9]. These structural changes are entirely unaccounted for in present theoretical models of LII. Preliminary results have indicated that the size of the primary particles remained generally unaltered and thus concerns of size dependent effects remain valid. Given these recent experimental observations of physical changes in the laser-heated soot [9], detailed calculations using existing models of LII to estimate the fractional contributions to the LII signal from different size soot particles at different times would be physically unrepresentative.

\section{Specific Objectives}

Here experiments were performed to identify the signal collection conditions under which either primary particle size or soot aggregate morphology minimally affect LII. These results are expected to be of general use since the range of primary particle size and aggregate morphology within a diffusion flame is likely to be representative of many other combustion processes, particularly those possessing uncharacterized soot primary particle sizes and/or aggregate morphology.

To discern under what combination of spectral and temporal collection conditions the LII signal was selfconsistent, radial LII intensity profiles from an ethylene/ air diffusion flame are detected at different time delays relative to the excitation laser pulse and at different detection wavelengths. They are then normalized with respect to the peak intensity within the annular region.

\section{Experimental}

A pulsed Nd:YAG laser provided light at $1064 \mathrm{~nm}$ for the LII measurements. An 8x Galilean telescope of spherical UV fused silica lenses followed by a pair of cylindrical lenses formed the laser beam into a sheet. Custom cylindrical lenses which were spherical instead of rectangular were used to prevent undesirable beam clipping and resulting diffraction effects in the laser sheet. Expansion of the laser beam to a dimension far greater than necessary allowed selection of the most uniform central 'slice' of the beam for these measurements. Typical intensities for the 1064, 532 and $266 \mathrm{~nm}$ light in the sheet were estimated to be $4 \times 10^{7}$, $1 \times 10^{7}$ and $1 \times 10^{6} \mathrm{~W} / \mathrm{cm}^{2}$, calculated using a $10 \mathrm{nsec}$ laser pulse width and sheet thickness of 750 microns for each wavelength. In addition to two-dimensional images, spectral and temporal scans of the LII signal were also performed with the laser beam formed into a sheet. By measuring the rate of convergence and divergence of the laser sheet, the presumed focal position was placed at the center of the burner.

Spectral and temporal scans of the laser-induced incandescence signal used a $1 / 4$ meter scanning mono-chromator fitted with a photomultiplier tube (PMT) as detector. A 1 -meter fused silica fiber optic cable directed either the LII or LIF signal to the monochromator with a $250 \mathrm{~mm}$ focal length spherical lens focusing the spatially integrated LII signal into the fiber-optic cable. A computer controlled boxcar integrator system was used for signal processing and data collection. A gated intensified camera fitted with an ultraviolet $\mathrm{f} 4.5 / 105 \mathrm{~mm}$ (adjustable) focal length camera lens and extension tube captured the LII images. Interference filters centered at 400,500 and $600 \mathrm{~nm}$ each with a nominal bandpass of $70 \mathrm{~nm}$ defined the spectral collection interval for LII measurements. Practical limits of obtaining large bandwith interference filters in the ultraviolet and adequate detection sensitivity of our camera at long wavelengths confined our measurements to this wavelength range. Spatially resolved and spatially integrated measurements were performed over a $19 \mathrm{~mm}$ vertical slice of the flame determined by the laser sheet height. To best compare LII intensities using different signal detection conditions, radial LII intensity profiles were obtained by averaging 20 pixel rows together yielding a spatial resolution of approximately $0.5 \mathrm{~mm}$ using a custom program. A frame-grabber with 16 MByte of on-board memory digitized the images for transfer to the host computer. Data reduction used commercially available software. Delay generators controlled the relative timing of the camera video signal, the firing of the laser, the camera detection gate and the boxcar data collection system for the measurements using the monochromator.

The burner, consisting of a central fuel nozzle surrounded by an air coflow, has been described previously [15]. Mass flow controllers provided an ethylene flow rate of $3.85 \mathrm{~cm}^{3} / \mathrm{sec}$ with a surrounding air coflow of $7.85 \mathrm{~cm} 3 / \mathrm{sec}$.

\section{Signal Detection Strategies}

For the spatially resolved measurements, six cases as shown in Fig. 1 were considered here for assessing the effect of the signal collection time upon the accuracy of the LII signal. While the Cases considered here are investigated using one-dimensional imaging, similar conditions and conclusions are expected to apply to both planar and 'point' measurements.

\section{Results \\ Spatially Integrated Measurements}

Figure 2 shows spectrally resolved LII emission scans obtained at an axial height of $38 \mathrm{~mm}$ above the burner using excitation wavelengths of 266,532 and $1064 \mathrm{~nm}$ light. The spectra are uncorrected for instrumental response. The slight dips near $400 \mathrm{~nm}$ (observable in the scan using $1064 \mathrm{~nm}$ excitation light) are characteristic of the response function of the (PMT). To maximize sensitivity for 


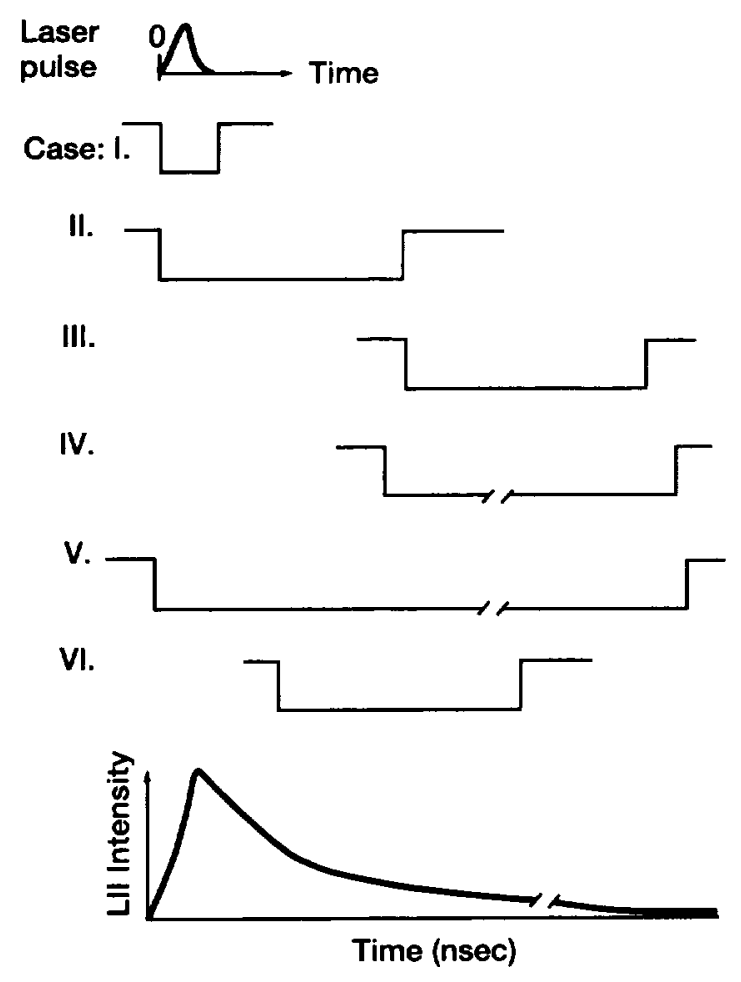

Figure 1.- In case 1 the LII signal is integrated over the laser pulse using a 25 nsec gate duration to maximize the signal-to-noise. In Case 2, the LIl signal is integrated over the laser pulse using a gate duration of $100 \mathrm{nsec}$ to provide higher signal. In Case 3, the LII signal is integrated over the laser pulse for $100 \mathrm{nsec}$ but starting $100 \mathrm{nsec}$ after the laser pulse to avoid detection of photochemical interferences. In Case 4 as in Case 3, signal detection starts 100 nsec after the laser pulse but thereafter the entire detectable Lll signal is integrated to achieve higher signal levels. In Case 5 the entire LII signal is integrated including during the laser pulse to achieve the highest signal level. In case 6 the LIl signal is integrated for 100 nsec as in Cases 2 and 3 but with signal collection delayed from the excitation laser pulse by only 50 nsec to achieve higher signal than Case 3 yet still avoid detection of photochemical interferences.

photochemical interferences, the spectra were obtained using a $10 \mathrm{nsec}$ detection gate centered over the peak of the LII signal. The broad and featureless emission spectrum using 1064 or $532 \mathrm{~nm}$ light is indicative of the absence of photochemical interferences and stands in stark contrast to the photochemical interferences produced by excitation at $266 \mathrm{~nm}$. Similar spectral interferences have been observed previously at these excitation wavelengths in premixed flames $[16,17]$. Prior work in premixed flames has similarly

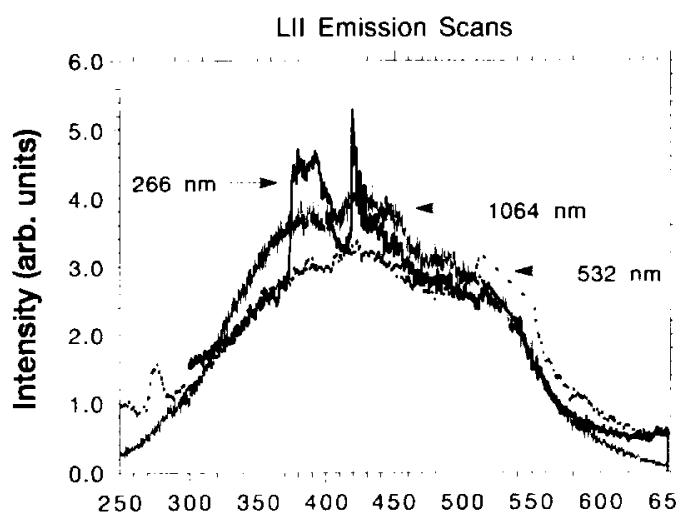

Wavelength, $\mathrm{nm}$

Figure 2.-Spectrally resolved emission scans of the LII signal spatially integrated using excitation wavelengths of 266,532 and $1064 \mathrm{~nm}$ at an axial height of $38 \mathrm{~mm}$ HAB. For each scan the detection bandwidth was approximately $1.2 \mathrm{~nm}$. Scattered light peaks at 266 and $532 \mathrm{~nm}$ were eliminated by blocking the detector as seen in the emission scans.

found that with $1064 \mathrm{~nm}$ excitation, LII signal collection coincident with the laser pulse is a viable detection strategy since photochemical interferences are absent [4].

\section{Spatially Resolved Measurements}

As is evident from Figs. 3(a) to 3(c), both Cases 1 and 2 are identical within experimental error despite the far longer (4x) signal collection time of Case 2 . However, delaying the signal collection time to occur after the laser pulse, as in Case 3 , results in a significant difference in the observed radial soot volume fraction profiles. As the detected wavelength increases from 400 to $600 \mathrm{~nm}$, the difference in the radial profiles between Cases 1 or 2 and Case 3 decreases. Still, the difference between Cases 1 (and 2) and 3 persists.

Figures 4(a) to 4(c) compare Cases 4 and 5 to the 'reference' Case 1. Clearly long signal collection times lead to rather different LII radial profiles presumably due to cooling effects dependent upon the particle size. Although integration over the initial portion of the signal decreases this dependence as illustrated by the smaller differences between Cases $5 \& 1$ versus Cases $4 \& 1$ as shown in Figs. 4(a) to 4(c), it does not entirely eliminate it. Interestingly, the difference between Cases 4 or 5 decreases with increasing detected wavelength.

Since photofragment fluorescence lifetimes are generally less than 10 nsec in atmospheric pressure flames, a less conservative laser pulse/detection gate delay of $50 \mathrm{nsec}$ may be entirely adequate to reject photofragment fluorscence from the LII signal. This possibility is considered as Case 6. A comparison of the Cases 2, 3 and 6 is made in Fig. 5. Case 2 was chosen for comparison such that all Cases considered in Fig. 5 utilized the same detection gate duration 

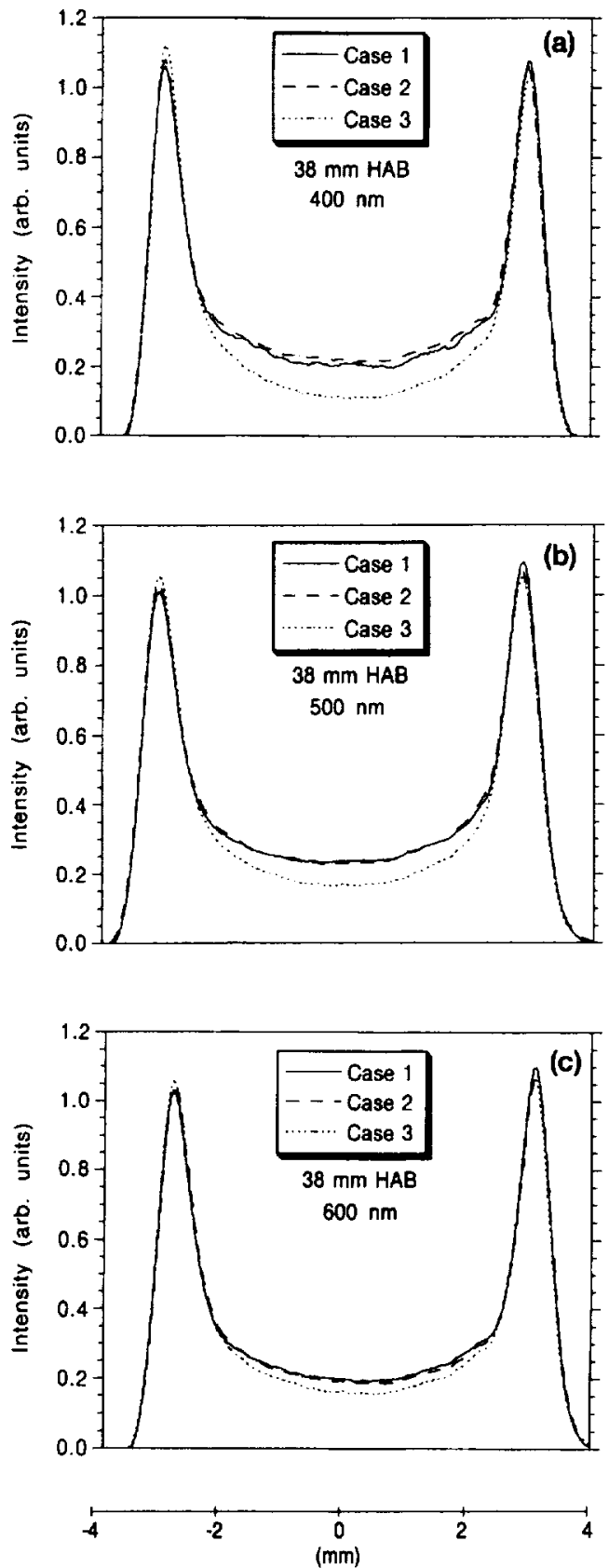

Figure 3.-Radial profiles of normalized LII intensity at $38 \mathrm{~mm} \mathrm{HAB}$ with center detected wavelengths at 400,500 and $600 \mathrm{~nm}$. Cases 1-3 are compared.

of $100 \mathrm{nsec}$. As seen in Fig. 5, the shorter delay between the excitation laser pulse and signal collection results in a closer correspondence between Cases 2 and 6 compared to Cases 2 and 3.

\section{Discussion}

Given the different final particle temperatures and cooling rates after the laser pulse which are both dependent
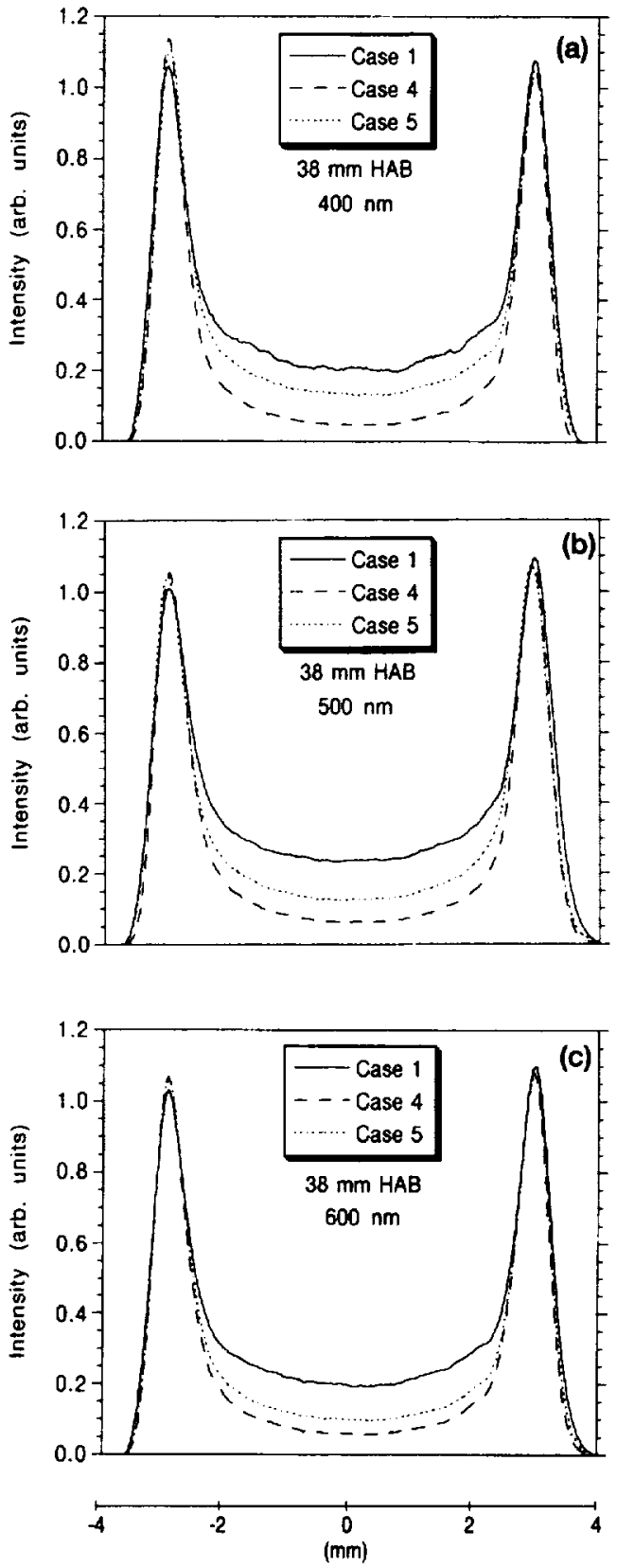

Figure 4.- Radial profiles of normalized LII intensity at $38 \mathrm{~mm}$ HAB with center detected wavelengths at 400,500 and $600 \mathrm{~nm}$. Cases 1, 4 and 5 are compared.

upon particle size, a detection gate delayed from the laser pulse such as in Case 3 clearly does not adequately reflect incandescence from primary particles of varying sizes. With smaller primary particles occurring along the centerline, lower signals compared to the annular region would be expected with detection times occuring after the excitation laser pulse. This is shown in the intensity differences between Cases 1 \& 2 and Case 3 in Figs. 3(a) to 3(c). Thus 


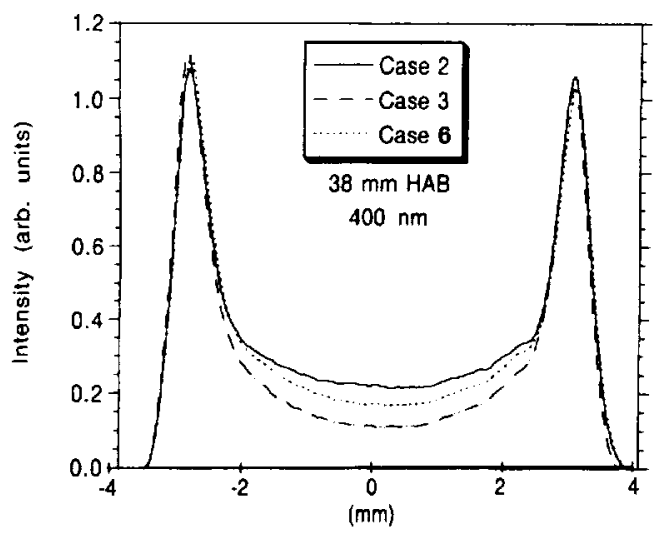

Figure 5.- Radial profiles of normalized LII intensity detected at $400 \mathrm{~nm}, 38 \mathrm{~mm}$ HAB. Cases 2, 3 and 6 are compared.

prompt detection coincident with the laser pulse is the most important factor in minimizing a particle size dependent bias in the LII signal. For reasonable detection periods of 25-100 nsec starting at the beginning of the excitation laser pulse (Cases 1 and 2 respectively) differences in the cooling rates of different size particles apparently is sufficiently small that negligible differences are produced in the LII signal as also seen in Figs. 3(a) to 3(c).

Larger particles, heated to higher final temperatures and cooling at slower rates compared to smaller particles at the same temperature contribute more to the LII signal with increasing times after the laser pulse. To achieve maximum signal intensity, long signal integration times may be used. Yet, even with detection integrating over the excitation laser pulse, (Cases 1 and 5) differences in the LII signal due to different size particles persists. This is clearly shown in the differences between Cases 1 and $4 \& 5$ in Figs. 4(a) to 4(c). However integration of the LII signal during the excitation laser pulse does help as shown by the smaller intensity differences between Cases 1 and 5 compared with Cases 1 and 4 in Figs. 4(a) to 4(c).

As discussed earlier, the LII signal will become increasingly biased towards the larger primary particles or aggregates in which they are contained with increasing time after the excitation laser pulse. Hence shorter time delays between the excitation laser pulse and signal collection should lessen sensitivity of the collected LII signal to particle size effects. This is observed in Fig. 5 where a shorter delay between the excitation laser pulse and signal collection results in a closer correspondence between the observed radial profiles, i.e., a closer correspondence is seen between Cases 2 and 6 than between Cases 2 and 3 . Yet a difference still persists between case 2 and 6 .

\section{Excitation Wavelength}

As the most consistent LII signals are obtained using a prompt detection gate that integrates over the laser pulse and for a short time period thereafter, a premium is placed on either minimization or preferably elimination of laserinduced photochemical interferences. Ultraviolet light has been widely recognized to cause severe photochemical interferences in both diffusion and premixed flames $[16,17]$. Among commonly available high pulsed power wavelengths, $1064 \mathrm{~nm}$ light is perhaps least likely to result in photchemical interferences. No gas-phase molecular transitions have been reported at this wavelength. To initiate molecular fragmentation at least a 3-photon absorption via this process is required. Such a nonresonant multiphoton transition possesses a very small transition probability [18]. Even if multiphoton absorption did occur, infrared multiphoton absorption generally results in photodissociation from the ground molecular state, a process which does not produce excited state photofragments [19].

\section{Detection Wavelength}

Visible and ultraviolet wavelengths have been shown to result in Swan band emisison of $\mathrm{C}_{2}$ fragments in both sooting diffusion and premixed flames $[16,17]$. Both photofragmentation of large molecules and/or vaporization of soot are likely sources of the photofragments. Interestingly, no emission of $C_{3}$ species or higher mass carbon clusters has been identified in these studies. $\mathrm{C}_{2}$ emission peaks of the $\Delta v=+1,0$ and -1 occur at 473,516 and $573 \mathrm{~nm}$ [20]. Since both theoretical considerations and our experimental results suggest that long wavelength detection is preferable, detection of LII at wavelengths greater than or equal to $600 \mathrm{~nm}$ is recommended. Significantly, most photodetectors have sufficiently high sensitivity within this wavelength region to make this a reasonable alternative to detection in the near ultraviolet.

\section{Conclusions}

Both the qualitative physical structure of soot aggregates and rigorous theoretical models of the absorption of soot aggregates indicate that the particle size relevant to LII should be considered that of the primary particle. To prevent introducing a particle size dependent bias in the LII signal, signal integration beginning with the excitation laser pulse is necessary. Signal integration times extending to 25 or $100 \mathrm{nsec}$ after the laser pulse do not produce significant differences in radial profiles of the LII signal due to particle size effects. Longer signal integration times extending hundreds of nanoseconds or signal integration times delayed from the excitation laser pulse reveal a decreased sensitivity to smaller primary particles. While long wavelength detection reduces the sensitivity of the LII signal to primary particle size, only prompt detection of the LII signal, beginning with the excitation laser pulse, can effectively minimize a primary particle size bias in the LII signal over the range of primary particle sizes encountered in a ordinary gas-jet diffusion flame. Excitation of LII using $1064 \mathrm{~nm}$ light is recommended to avoid creating photochemical interferences thus allowing LII signal collection to occur during the excitation pulse without spectral interferences. In addition to minimizing sensitivity to primary particle size, long wavelength detection further safeguards against photochemical interferences contributing to the detected LII signal. 


\section{Acknowledgements}

The author acknowledges support under NASA contract NAS3-27186. Special thanks are extended to Mr. Kirk Jensen (graduate researcher at the University of Illinois at Chicago) for providing the computer program for obtaining radial intensity profiles from the LII images.

\section{References}

1. Dec, J.E, zur Loye, A.O. and Siebers, D.L., SAE TP910224 (Society of Automotive Engineers, Warrensdale, PA, 1991).

2. Pinson, J.A., Mitchell, D.L., Santoro, R.J. And Litzinger, T.A., SAE TP-932650 (Society of Automotive Engineers, Warrensdale, PA, 1993).

3. Quay, B., Lee, T.W., Ni, T. and Santoro, R.J., Combust. And Flame 97:394 (1994).

4. Vander Wal, R.L. and Weiland, K.J., J., Appl. Phys. B59:445 (1994).

5. Ni, T., Pinson, J.A., Gupta, S. and Santoro, R.J., Appl. Opt. 34:7083 (1995).

6. Shaddix, C.E., Harrington, J.E. and Smyth, K.C., Combust. and Flame 99:723 (1994).

7. Vander Wal, R.L., Choi, M.Y. and Zhou, Z. Combust. and Flame (accepted).
8. Vander Wal, R.L. and Dietrich, D.L., Appl. Opt. 34:1103 (1995).

9. Vander Wal, R.L., Choi, M.Y. and Lee, K.-O., Combust. and Flame 102:200 (1995).

10. Will, S., Schraml, S. and Leipertz, A., Opt. Letters 20:2342 (1995).

11. Eckbreth, A.C., J. Appl. Phys. 48:4473 (1977).

12. Melton, L.A., Appl. Opt. 23:2201 (1984).

13. Dasch, C.J., Appl. Opt. 23:2209 (1984).

14. Hofeldt, D.L., SAE TP-930079 (Society of Automotive Engineers, Warrendale, PA, 1993).

15. Santoro, R.J., Semerjian, HG. and Dobbins, R.A., Combust. and Flame 51:203 (1983).

16. Bengtsson, P.-E. and Alden, M., Combust. Sci. and Technol. 77:307 (1991).

17. Beretta, F., D.'Alessio, A., D'Orsi, A. and Minutolo, P., Combust. Sci. and Technol. 85:455 (1992).

18. Kliger, D.S., "Ultrasensitive Laser Spectroscopy," Academic Press, New York, (1983).

19. Letokhov, V.S.,"Nonlinear Laser Chemistry: IRMPD," Bristol, New York (1985).

20. McDonald, J.R., Baronavski, A.P. and Donnelly, V.M., Chem. Physics 33:161 (1978). 
Public reporting burden for this collection of information is estimated to everage 1 hour per response, including the time for reviewing instructions, searching existing data sources, gathering and maintaining the data needed, and completing and reviewing the collection of information. Send comments regarding this burden estimate or any other aspect of this Davis Highway, Suite 1204, Arlingtan, VA 22202-4302, and to the Office of Management and Budget, Paperwork Reduction Project (0704-0188), Washington, DC 20503.

\begin{tabular}{|l|c|c|}
\hline 1. AGENCY USE ONLY (Leave blank) & $\begin{array}{r}\text { 2. REPORT DATE } \\
\text { May } 1996\end{array}$ & $\begin{array}{r}\text { 3. REPORT TYPE AND DATES COVERED } \\
\text { Final Contractor Report }\end{array}$ \\
\hline
\end{tabular}

4. TITLE AND SUBTITLE

5. FUNDING NUMBERS

Laser-Induced Incandescence: Detection Issues

WU-963-70-0E

6. AUTHOR(S)

C-NAS3-27186

Randall L. Vander Wal

7. PERFORMING ORGANIZATION NAME(S) AND ADDRESS(ES)

8. PERFORMING ORGANIZATION REPORT NUMBER

NYMA, Inc.

2001 Aerospace Parkway

E-10189

Brook Park, Ohio 44142

10. SPONSORING/MONITORING AGENCY REPORT NUMBER

National Aeronautics and Space Administration

Lewis Research Center

NASA CR-198470

Cleveland, Ohio 44135-3191

\section{SUPPLEMENTARY NOTES}

Prepared for the Central States Section Meeting sponsored by The Combustion Institute, St. Louis, Missouri, May 5-7, 1996. Project Manager, Howard D. Ross, Space Experiments Division, NASA Lewis Research Center, organization code $6711,(216) 433-2562$.

12a. DISTRIBUTION/AVAILABILITY STATEMENT

12b. DISTRIBUTION CODE

Unclassified - Unlimited

Subject Category 23

This publication is available from the NASA Center for AeroSpace Information, (301) 621-0390.

\section{ABSTRACT (Maximum 200 words)}

Experimental LII measurements were performed in a laminar gas-jet flame to test the sensitivity of different LII signal collection strategies to particle size. To prevent introducing a particle size dependent bias in the LII signal, signal integration beginning with the excitation laser pulse is necessary. Signal integration times extending to 25 or $100 \mathrm{nsec}$ after the laser pulse do not produce significant differences in radial profiles of the LII signal due to particle size effects with longer signal integration times revealing a decreased sensitivity to smaller primary particles. Long wavelength detection reduces the sensitivity of the LII signal to primary particle size. Excitation of LII using $1064 \mathrm{~nm}$ light is recommended to avoid creating photochemical interferences thus allowing LII signal collection to occur during the excitation pulse without spectral interferences.

\begin{tabular}{|c|c|c|}
\hline \multicolumn{3}{|c|}{ IBJECT TERMS } \\
\hline \multicolumn{3}{|c|}{ Laser-induced incandescence (LII) } \\
\hline 17. & $\begin{array}{l}\text { SECURTY CLASSIFICATION } \\
\text { OF REPORT }\end{array}$ & $\begin{array}{l}\text { 18. SECURITY CLASSIFICATION } \\
\text { OF THIS PAGE }\end{array}$ \\
\hline & Unclassified & Unclassified \\
\hline
\end{tabular}

NSN 7540-01-280-5500

\begin{tabular}{|c|c|}
\hline \multirow{2}{*}{} & $\begin{array}{c}\text { 15. NUMBER OF PAGES } \\
8\end{array}$ \\
\cline { 2 - 2 } & $\begin{array}{c}\text { 16. PRICE CODE } \\
\text { A02 }\end{array}$ \\
\hline $\begin{array}{c}\text { 19. SECURITY CLASSIFICATION } \\
\text { OF ABSTRACT } \\
\text { Unclassified }\end{array}$ & 20. LIMITATION OF ABSTRACT \\
\hline
\end{tabular}

Standard Form 298 (Rev. 2-89) Prescribed by ANSI Std. Z39-18 298-102 



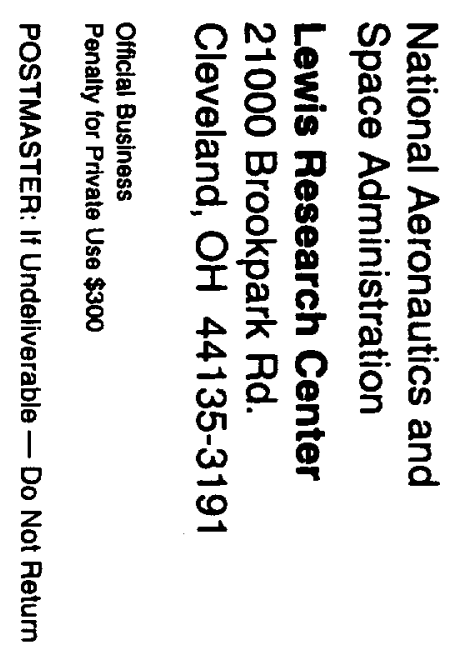

